\title{
Heterogeneity in Anxiety Disorder and Autism Spectrum Disorder: Difference and Overlap
}

\author{
Ziadatul Hikmiah \\ Department of Psychology, Universitas Brawijaya, Malang, Indonesia
}

\begin{abstract}
Research on the expression and prevalence of co-occurring anxiety disorders and autism spectrum disorders (ASD) has produced variable results. In part this is due to heterogeneity in the characteristics of the samples, methodology, and the underlying cause of anxiety disorders and ASD across studies. This review will focus on the aspects related to the manifestation of anxiety disorders in children with autism spectrum disorder (ASD), in order to establish the amount of comorbidity or heterogeneity both within and between these disorders. This review will also elaborate on the findings from related studies with reference to the underlying causes of both disorders. A number of typical anxiety symptoms play a significant role characterising autism, creating overlap and heterogeneity in the disorders. Therefore, further research on the measurement of anxiety symptoms in children and adolescents with ASD in addition to the interaction of anxiety and social disability in this population is required, so appropriate treatment and intervention can be established to address each specific characteristic of these disorders.
\end{abstract}

Keywords: heterogeneity, Anxiety Disorder, Autism Spectrum Disorder

\section{Introduction}

\subsection{Anxiety disorder}

Anxiety disorder is purportedly the most common disorder in typically developed children and adults (Ozsivadjian \& Knott, 2011) with a prevalence rate which varies from $2.5 \%$ in the US (Cartwright-Hatton et al., 2006), to as high as $41.2 \%$ in Japan. However, it should be noted that the review did not elaborate on the cultural differences regarding each study, which is essential, in order to generalise the prevalence rates with respect to the global population.

Anxiety manifests in children in the form of transient worry and stress (Scaini et al., 2014). In several developmental stages, certain types of anxiety are extremely common and therefore are seen as being normative; for instance, separation anxiety in 12-18 months infants. However, anxiety disorders can be differentiated from 'normal' fears and worry based on the severity of symptoms (Eussen et al., 2013), persistence and impact on functioning (O'Toole et al., 2013). Compared to individuals who do not develop anxiety disorders, those who

* Corresponding author: Ziadatul Hikmiah

ziadatulhikmiah@ub.ac.id

Published online at http://IJDS.ub.ac.id/

Copyright @ 2019 PSLD UB Publishing. All Rights Reserved develop anxiety disorders demonstrate more fearful, anxious and avoidant behaviours in early childhood (Przeworski et al., 2011).

Anxiety disorders are commonly diagnosed with self-report measures, such as IAS, LSAS and FNE. However, due to the heterogeneity of the disorders, not all psychometric cues are encompassed by these self-report measures. Modini et al., (2015) conducted analysis by means of 78 studies regarding self-report measures related to anxiety, which revealed that there is an absence of evidence to support a number of psychometric properties for measures through the studies and moreover, most of the measures are still based on DSM IV criteria and have not yet been updated to the DSM V criteria. Thus, further research is required to establish the psychometric properties of trait social anxiety self-report measures prior to their results being interpreted as robust indices of this significant construct (Modini et al., 2015).

The cause of anxiety disorder is quite heterogeneous. From meta-analytic estimates using twin design, Scaini et al., (2014) suggested that genetic factors and non-shared environmental factors explain most of the individual differences in anxiety disorders. 
Research on family studies have identified that families of patients with anxiety disorders manifest higher rates of anxiety than families of the normal control population (Gadow et al., 2010). This indicates that children of parents with anxiety are more likely to develop anxiety in the future. Other than the propensity for genetic transmission, parents may subconsciously reinforce anxiety through protective parental behaviour, negative evaluation (Schreier \& Heinrichs, 2010) and by discouraging pro-social behaviour (Dadds et al., 1996). Other environmental factors such as early memories of traumatic experience (Nilsson et al., 2012) and negative self-image (NaragonGainey \& Watson, 2011) also contribute to the heterogeneity of anxiety disorders. Due to this heterogeneity of differences, individuals with anxiety disorders are classified into groups or clusters based on their distinctive behaviours. For example, Przeworski et al., (2011) assessed interpersonal sub-types among individuals with anxiety disorders and yielded 4 replicable clusters, identified as: intrusive, exploitable, cold and non-assertive sub-types. This categorisation assists with distinguishing each type of anxiety disorder and with decisions pertaining to appropriate treatment.

The symptoms of anxiety disorders encompass a wide array of aspects. Using a cognitive behavioural approach to anxiety, the clinical features of anxiety may be conceptualised as physiological, cognitive, emotional and behavioural (Ozsivadjian et al., 2012). Physiological changes consist of somatic complaints, such as nausea, headaches, sweating and muscle tension (Modini et al., 2015; Scaini et al., 2014), whilst the emotional component encompasses feelings of fear, worry, dread or irritability (Przeworski et al., 2011). Furthermore, cognitive symptoms frequently reflect catastrophic predictions and expectations of failure to cope. Finally, the predominant behavioural symptom of anxiety is avoidance, although hyper vigilance is also common (Bejerot et al., 2014; Eussen et al., 2013).

\subsection{Manifestation of anxiety disorder in individuals with ASD}

Autism by nature is very heterogeneous and is a combination of abnormalities in language, social cognition and mental flexibility (Kerns \& Kendall, 2012). ASD has been associated with complex genetic specificity, which leads to abnormalities, with approximately 10-20 genes collectively accounting for 10-20\% of ASD cases (Kumar et al., 2007; Chung et al., 2011; Geschwind, 2011). Moreover, clinical diagnosis of ASD has been conducted by observing specific behavioural cues, such as repetitive patterns of behaviour, interests, or activities, and deficits in social communication and social interaction across multiple contexts (American Psychiatric Association, 2013). However, these core characteristics of ASD are very similar to a number of significant symptoms related to anxiety disorders (Hallett et al., 2013; Vasa et al., 2013; McPheeters et al., 2011; Kerns \& Kendall, 2012), which manifest in behaviour, for instance having a predisposition to being quiet in social activity and demonstrating social withdrawal (Bejerot et al., 2014).

Consequently, the manifestation of anxiety disorders in ASD may lead to confusion, as both disorders share numerous symptoms and types of behaviours, resulting in difficulties in establishing clinical diagnosis (Scattone \& Mong, 2013). Across studies, ASD is regularly clinically diagnosed using Autism Diagnostic interview-Revised (ADI-R) and ADOS (Hallett et al., 2013; Bejerot et al., 2014; Maddox \& White, 2015; Eussen et al., 2013). However, these measures are not based on aetiology but on expert observation and assessment of behaviour and cognition. They can be considered arbitrary; therefore, which category a person fits into depends partially on subjective criteria (Geschwind, 2011). Furthermore, uncertainty in connection with diagnosis may lead to delays in establishing ASD and numerous diagnoses of anxiety disorders. According to the study conducted by Rydén \& Bejerot, (2008), 17\% of adult psychiatric outpatient sample were diagnosed with anxiety disorders prior to establishing ASD. Even though the study lacked a large enough sample size to make a generalisation, the findings describe the implication of comorbidity in ASD.

For the individual with ASD, comorbidity of anxiety disorders has a profound impact on their everyday functioning and the symptoms of both conditions may negatively influence each other. Thus, treating anxiety disorders can provide an improvement in the everyday functioning of individuals with ASD (Eussen et al., 2013). Therefore, in order to decide the most 
effective and appropriate treatment and intervention, further understanding of the underlying cause is required to obtain a greater understanding of the disorders.

Like other neuro-developmental disorders, the underlying cause of anxiety disorder in ASD arises from the combination of biological, psychosocial and environmental aspects. Abnormalities in parts of the brain which control emotion or the amygdala (Amaral et al., 2003) may be associated with anxiety in ASD (Frick et al., 2014), which emphasises the neurological cause of anxiety in ASD. Furthermore, individuals with ASD are prone to experiencing anxiety symptoms, due to their significant communication and social deficits (e.g., difficulty understanding social cues), heightened sensory sensitivity and difficulty regulating emotions (Ung et al., 2015). Specifically, high functioning individuals with ASD are associated with increased levels of anxiety because they are more aware of their own social and emotional deficits, and therefore feel more anxious (e.g. Bellini, 2006). Due to these heterogeneous symptoms and causes, autistic individuals are classified based on the severity of the symptoms, which are social communication impairments and restricted repetitive patterns of behaviour (American Psychiatric Association, 2013).

Possible causes of anxiety in ASD are varied across literature. This variety is principally due to the number of the sample, the methodology and the measures being used in the studies. Various causes of this comorbidity result in a range of behaviours, which can be different from person to person (de Bruin, 2007). To attain an in depth understanding regarding the comorbidity of anxiety symptoms in ASD, identifying the nature of each overlapping aspect is crucial.

\section{Comorbidity and heterogeneity}

This section will elaborate on three aspects of anxiety disorders and ASD which overlap; specifically repetitive behaviour, social anxiety and social withdrawal, besides the possible causes and heterogeneity of each aspect.

\subsection{Repetitive behaviour}

Repetitive behaviour patterns of occurrence and severity characterise autism spectrum disorders. According to DSM V, one of the diagnostic aspects of autism is if an individual demonstrates restricted, repetitive patterns of behaviour, interests or activities, e.g., stereotyped or repetitive motor movements, inflexible adherence to routines, ritualised patterns or verbal nonverbal behaviour (American Psychiatric Association, 2013). Repetitive behaviour in autism spectrum disorders has been proven through empirical studies in addition to anecdotal evidence. The longitudinal study conducted by Wolff et al., (2014) established that toddlers who develop a high risk of ASD begin to reveal atypical repetitive behaviours as early as 12 months of age. In this study, the researchers included 253 children, who were grouped based on risk status and diagnostic outcome. This study followed participants up to the age of 2 and based diagnostic classification upon assessments performed at that time. The result of this study is consistent with the study conducted by Arnott et al., (2010) that repetitive behaviour in 2 year old toddlers may represent early signs of ASD.

Anecdotal evidence predominantly comes from parents or caregivers based on their observation of their family member with ASD. In a focus group study of 17 parents of 19 autistic children, (Ozsivadjian et al., 2012) ascertained that a number of parents reported an increase in sensory, obsessional and repetitive/stereotyped behaviours at times of anxiety, for example: 'Depending on how anxious he is, all the trains have to go into their station: it eats up time and gets you so frustrated'; 'He homes in on a subject and it becomes so intense'; ' $J$ will repeat questions, the same question over and over again until she's satisfied with the answer'.

As one of the core characteristics of ASD, repetitive behaviour has been commonly associated with anxiety (Wolff et al., 2014). Furthermore, several large studies of young people with ASD established positive associations between anxiety and severity of ASD symptomatology (e.g. Sukhodolsky et al., 2007). The severity of repetitive behaviour in individuals with ASD is determined by the level of anxiety in the particular person (Rodgers et al., 2012), as children with high levels of anxiety have more obvious repetitive behaviours than those without/lower levels of anxiety. Specifically, Rodgers and his colleagues also determined that ASD individuals with increased anxiety are associated with intensity of insistence of sameness, such as insisting that 
everything in the house stays the same; while those with lower anxiety levels are associated with sensory motor repetitive behaviour, e.g, spinning around and flapping arms. However, this study is limited as it only recruited ASD individuals with an average IQ. Undoubtedly this finding is unlikely to be generalised in the wider ASD population, for example people with ASD with a higher or lower IQ. However, the result of the study by Rodgers et al., is consistent with the result of a study conducted by Bodfish et al., (2000), who performed research using the Autism Behaviour Checklist and Repetitive Behaviour Scale to compare the variety of repetitive behaviours in individuals with ASD and Intellectual Disability, and ascertained that the severity of repetitive behaviours predicted severity in autism. Furthermore, there is evidence that the occurrence of repetitive behaviours in autism may be mediated by the level of cognitive ability. Thus, it can be inferred that repetitive behaviours in ASD may be directly associated with anxiety level and intelligence.

Regarding possible biological causes, Gadow et al., (2010) attempted to discover the relationship between repetitive behaviour in ASD with a certain genotype (DRD4). They recruited 67 subjects with ASD and grouped them based on genotype. However the result was inconclusive, until Staal et al., (2012) conducted a similar experiment with a larger sample size and disclosed that gene DRD3 revealed a significant association, which caused repetitive behaviours in ASD, particularly insistence of sameness. However, this study requires replication with an even larger sample considering that the result may change in a sample size that is more extensive. In a further study, Muehlmann \& Lewis, (2012) argue that neural system dysfunction mediates repetitive behaviours in anxiety and ASD, specifically in the area of the cortical basal ganglia pathway which controls motor movements. These studies indicated that manifestation of repetitive behaviours in ASD may be contributed to by a biological cause.

Besides gene and neurobiological characteristics, age is a determining factor in repetitive behaviours in individuals with ASD. In a study by Esbensen et al., (2009), over 700 individuals with ASD were rated on the Repetitive Behaviour Scale-Revised. The result determined that repetitive behaviours were less frequent and less severe among older than younger individuals, confirming that autism symptoms decrease with age. This finding is consistent with previous studies which stated that several core symptoms of ASD reduce as the person becomes older (Shattuck et al., 2007; Seltzer et al., 2010). However, this study simply compares ASD individuals in different age groups (cross-sectional) instead of following the developmental trajectory, ignoring the possibility of heterogeneity of individual patterns of symptoms.

In contrast, in anxiety disorder itself, repetitive behaviours commonly experienced at a cognitive level, e.g. repetitive negative thoughts (Watkins, 2008), manifest in the form of worry, rumination and habitual negative selfthinking. Repetitive negative thought in anxiety disorder is caused by compulsive focus of attention on thoughts that cause feelings of sadness, anxiety and distress (Mellings \& Alden, 2000). However, it is still uncertain whether repetitive thoughts cause anxiety or vice versa.

In conclusion, repetitive behaviours are more heterogeneous and evident in wider aspects in ASD than in anxiety disorder, as it is a core characteristic of ASD. Repetitive behaviour in ASD is also related to a more complex association with many aspects, such as the severity of the symptoms, level of intelligence and age.

\subsection{Social anxiety}

According to DSM V, social anxiety is one of the sub-types of anxiety disorders, where a person experiences irrational fear or anxiety specific to social settings (American Psychiatric Association, 2013). The essential feature of social anxiety is an intense fear of social situations or performance situations, where embarrassment may occur (Bellini, 2006). Social anxiety appears in physiological signs, e.g. increasing heartbeat, blushing and nervousness, as well as behavioural cues, such as difficulties with social interaction and even making eye contact. Furthermore, social anxiety can also be experienced at a cognitive level, for instance feeling personal distress and worry (Helverschou \& Martinsen, 2011)

Like many other mental health conditions, social anxiety disorder possibly arises from the complex interaction of environment and genetic causes (Scaini et al., 2014). Various studies have established possible heterogeneous causes of 
social anxiety disorder, such as genetic and hereditary factors (Stein \& Stein, 2008), parenting styles and attachment (NaragonGainey \& Watson, 2011; Herren et al., 2013), and other causes, for example peer relationship and deficits in social skills (Crawford \& Manassis, 2011). However, there is no clear explanation as to how much these characteristics contribute to the severity of the disorder.

A study using neuroimaging and behavioural data ascertained that damage or lesions in the amygdala may have heightened the response to irrational fear, causing increased anxiety in social situations (Amaral, 2002). Even though this study was conducted in nonhuman primates (macaque monkeys), this species has a similar brain structure and typical social interaction expression as humans. This study offers a fundamental insight and will help in understanding the amygdala's role in human social behaviour and in psychopathology such as social anxiety. In addition, as technology has become more advanced, Frick et al., (2014) conducted a neurological study to investigate the possibility of distinguishing social anxiety disorders patients $(n=14)$ from healthy controls ( $\mathrm{n}=12$ ) using a SVM (Support Vector Machine). The results support the belief that social anxiety disorder is a brain linked disorder, characterised by abnormal processing in the fear network with more diffuse abnormalities, which only affect a regional part, the grey matter area, as opposed to affecting the whole brain.

Other than neurological abnormalities, social anxiety is also associated with a decreased ability to understand complex emotions than to recognise basic emotions (O'Toole et al., 2013). Empirical studies have determined that poor knowledge of interpersonal emotion is associated with poor social competence (e.g. Helverschou \& Martinsen, 2011). Emotional knowledge is an essential aspect which enables individuals to undertake social interaction, and that due to social inhibition characterizing individuals with SAD (Schneier et al., 2011), it could be hypothesised that they are particularly unwilling to share their emotions with others, and therefore, are less likely to learn about and to fully understand their own and other's emotions.

Individuals with Autism Spectrum Disorders also commonly experience social anxiety disorder with a prevalence rate up to 17\% (Hallett et al., 2013). ASD individuals with social anxiety also demonstrate similar signs with typical behaviours of socially anxious individuals, such as avoiding eye contact, illustrating nonverbal nervousness and fidgeting, and difficulties in social communication (Tyson \& Cruess, 2012). In a study comparing ASD with typically developed subjects, Bejerot et al., (2014) established that the group with ASD had an increased level of social anxiety compared to the control group. Specifically, a number of studies ascertained that social anxiety principally occurs in individuals with high functioning ASD (e.g. White et al., 2012; Sukhodolsky et al., 2007; Bellini, 2006). This is for the reason that high functioning ASD individuals have more awareness with respect to their own social difficulties, which leads to more worry and fear of being negatively evaluated by others. Furthermore, Eussen et al., (2013) established that high functioning ASD individuals with a lower severity of symptoms and inferior social relationships will experience higher levels of social anxiety.

This theory is confirmed by an empirical study conducted by Maddox \& White, (2015), which revealed that many adults with ASD are aware of their social difficulties and experience impairing social anxiety. However, these findings are still vague considering the probability that high functioning ASD individuals report higher levels of social anxiety because they are more able to verbally express their feelings using self-reporting measures (Bellini, 2006, Sukhodolsky et al., 2007) compared to those with more severe symptoms of ASD with communication difficulties, who depend on the observer-report scale. Furthermore, when assessing social anxiety in individuals with ASD, many studies (e.g. Eussen et al., 2013) depend greatly on observable physiological indicators (e.g. trembling voice, avoiding eye contact) and ignoring the influence of socially anxious cognition. A more appropriate approach should be undertaken, so as to obtain a comprehensive assessment of social anxiety disorder in individuals with ASD, who have limited expressive language (Maddox \& White, 2015).

It is also worth noting that several studies have revealed that biological factors also contribute to the cause of social anxiety in individuals with ASD. A family study conducted by Piven \& Palmer, (1999) using 
semi-structured and family history interviews established higher than expected frequencies of $\mathrm{SAD}$ in first-degree relatives of autistic individuals, which suggests a possible common genetic link. Amaral et al., (2003) who previously conducted a study of the amygdala in social anxiety disorders in 2002, discovered that if the amygdala is abnormal in individuals with ASD, it may contribute to their abnormal fears and increased anxiety rather than their abnormal social behaviour. As in social anxiety disorder, it is still uncertain how much the manifestation of social anxiety in ASD may be due to genetics and how much is due to environmental causes.

Apparently, a number of the primary causes and behavioural characteristics appear similar in both disorders. These features do overlap in some ways, but are aetiologically and theoretically distinct in ways that current diagnostic measurements cannot always capture. Until now, attempts to differentiate ASD and social anxiety have relied heavily on diagnostic scales (e.g. Social Responsiveness Scale/SRS Cholemkery et al., 2014). Nevertheless, scales like these need to be retested on the wider population, in order to improve its validity and diagnostic accuracy. Moreover, diagnosis of social anxiety and ASD in adolescence and adulthood may become increasingly more difficult as maturation may lead to reduced symptom severity or more subtle deficits (Trammell et al., 2013). Therefore, modified scales to test for a co-morbid diagnosis of social anxiety in individuals with autism are needed.

In a review of empirical studies, social anxiety disorder and ASD differ in subtle ways: (1) eye contact and nonverbal behaviours, (2) social cognition and emotion processing, (3) relating and communicating in a social context and (4) neural and genetic bases of these behavioural impairments (Tyson \& Cruess, 2012). In comparison to individuals with ASD, individuals with social anxiety disorder still manage to focus on specific anxiety-arousing social interaction situations and the related thoughts and behaviours, whereas individuals with ASD tend to have more embedded socialisation impairments in general. Furthermore, In contrast to the generally poor quality of friendship in ASD, anxious children usually have friends, although their friendships may lack the intimacy and synchrony of friendships between children who are not socially anxious (Schneider, 2009). Further exploration into understanding the behavioural and biological connections between ASD and social anxiety will lead to improved understanding of these disorders' developmental trajectories, differential diagnoses and significantly, effective treatments.

\subsection{Withdrawal}

Autism Spectrum Disorder (ASD) is a group of heterogeneous conditions with social disability as the core feature. An empirical study on 328 children with ASD discovered that an increase in the severity of ASD symptoms is associated with poorer social skills (Cervantes \& Matson, 2015). Individuals with ASD repeatedly have difficulty processing information related to others and make social inferences based on facial expression, voice tone and social language (White \& Roberson-Nay, 2009). As previously elaborated upon, these social difficulties often lead to social anxiety, and one of the most apparent symptoms manifests in the form of social withdrawal and avoidance. Avoidance and withdrawal is a common behaviour in ASD as a sign of stress and anxiety, where the individual withdraws or disengages from social situations, and moreover, avoids specific situations, events or people (Cervantes \& Matson, 2015).

Anecdotal evidence from parents reported that children with ASD experience withdrawal and avoidance. A focus group study (Ozsivadjian et al., 2012) obtained numerous comments pertaining to avoidance or withdrawal at times of anxiety: 'He becomes unreachable you can just feel he's close to boiling point'; 'When she's anxious, she tries to close herself off and roll into a ball, you know, the smallest I can become'; 'At school last year, I didn't realise he was spending most of his time actually hiding under the table or behind the trolley.

Social withdrawal in anxious individuals appears in behaviour such as avoiding eye contact. In persons with social anxiety disorder, gaze aversion appears to be primarily related to regulation of social anxiety (Schneier et al., 2011). A person with social anxiety tends to make less eye fixation (Baker \& Edelmann, 2002), which others may misinterpret as gaze avoidance by the person with SAD or as a sign of disinterest, which consequently diminishes opportunities for positive social interaction (Maddox \& White, 2015). This behaviour is very similar to those of ASD individuals who tend to 
avoid eye contact and other emotional parts of the face (Gross, 2004).

Besides avoiding gaze, socially anxious individuals illustrate impairments in social behaviours, for instance social disinterest, detachment, avoidance or withdrawal despite evident competence (Kyriakopoulos et al., 2014). In ASD individuals, self-selective listening response is also correlated with signs of social withdrawal, which can be detected as early as three years old (Klin, 1991). In this classic experiment, infants were exposed to maternal voices and random noise. The group of typically developed toddlers would naturally show an interest and were attracted to their mothers' voices, while toddlers in the ASD vulnerable group demonstrated no interest. This finding indicates that self-selective listening in toddlers might be one of the important cues with respect to early ASD diagnosis, which reflects avoidance of social cues.

Similar to the causes of social anxiety, one of the possible causes of withdrawal in ASD individuals is parenting style. Specifically, withdrawal behaviour resulting from impaired attachment or from intense and prolonged approach-avoidance (Buitelaar, 1995). Despite the similarity of the behaviour and cause, avoidance and withdrawal in the ASD population appears more severe than those in socially anxious individuals without ASD. Comorbidity of social anxiety in ASD might contribute to social avoidance and limit the child's opportunities to practice appropriate social skills. One of the implications of this problem is the high rate of loneliness among the ASD population (White \& Roberson-Nay, 2009), especially those with high functioning $\mathrm{ASD}$, as they are liable to have more awareness regarding their social deficits.

\section{Diagnosis and treatment implications}

Understanding the comorbidity in addition to heterogeneity of anxiety disorders and ASD is important to determine the most effective and appropriate treatment based on an individual's unique symptoms and deficits. Nevertheless, before deciding on the appropriate treatment a robust diagnosis should be completed. Conversely, given that both disorders are heterogeneous as well as overlapping, diagnosis is not an easy task to perform. The problem related to recognising anxiety in people with autism and ID is related to at least four factors: (1) the tendency to overlook the manifestation of anxiety disorder in autism, (2) the overlap of symptoms between anxiety and autism, (3) the overlap between anxiety and other comorbid psychiatric disorders in autism, and (4) the tendency to rely heavily on indirect measures (e.g. observation or parent-report scale) in low-functioning ASD because of their communication difficulties (Helverschou \& Martinsen, 2011).

Furthermore, currently the tools and scales to measure levels of anxiety specifically in ASD population appear to be inadequate. Due to the heterogeneity of symptoms and causes, several measures may not successfully diagnose the symptoms of anxiety experienced by those with ASD. For example, common anxiety triggers for this population include changes in routine (e.g., class schedule, traffic, changing schools) and social situations (fear of being ridiculed and of being the centre of attention), which are typically not included in anxiety rating scales (Scattone \& Mong, 2013).

Addressing those problems can be undertaken by establishing robust measures which encompass somatic and cognitive traits of anxiety disorders in autism. Somatic traits such as hyperventilation and shivering in anxiety are relatively easy to observe; however, cognitive traits, for example personal distress and worries are best-measured by self-reporting measures, which not all autistic individuals can manage due to language impairments. Therefore, the use of multimodal assessment strategies appears appropriate (MacNeil et al., 2009). Such strategies imply combining anxiety schedules or checklists with direct observations, interviews with the family and other key informants, and physiological measurements, such as the heart rate (Helverschou \& Martinsen, 2011).

Additionally, a neurodevelopmental assessment strategy may also make a significant contribution to diagnosing both disorders. For example, a diagnostic approach applying brain imaging strategy to detect biomarkers for ASD resulted in an exceedingly high level of accuracy to make a clear distinction between ASD and other comorbid disorders (Ingalhalikar et al., 2014). Furthermore, a current study using multiple brain imaging modalities (structural 
MRI, DTI, and 1H-MRS) resulted in 91.9\% classification accuracy and enhanced information on the neural characteristics most relevant to the disorder (Libero et al., 2015). Through these multifaceted diagnostic approaches, each symptom and characteristic could be distinguished and effective treatment strategies could then be established to the level of individual heterogeneity.

The impact of anxiety was frequently reported to be more substantial than the impact of ASD (Ozsivadjian et al., 2012), therefore treating anxiety in ASD can significantly enhance quality of life. Anecdotal findings from parents of ASD individuals reported that their children had great difficulty expressing their worries verbally and most demonstrated their anxiety through changes in their behaviour (Ozsivadjian \& Knott, 2011). Current interventions may include medication, individual counselling, and advice for parents, or increasingly, several forms of cognitive behaviour therapy (CBT). In addition, highly anxious individuals, in particular those with social anxiety disorder, reveal cognitive distortions (Alkozei et al., 2014). Therefore, intervention related to cognitive construct may be of particular relevance to the presentation and/or maintenance of anxiety disorder in individuals with ASD.

Cognitive behaviour therapy (CBT) is considered to be the primary nonpharmacological treatment for anxiety and depression in typical individuals. CBT teaches people to recognize and modify maladaptive thought patterns to alleviate their anxiety (Gaus, 2011). However, the ability of young people with ASD to access various components of CBT treatment can be limited by their specific neuropsychological deficits in cognition, difficulties with communication, social understanding and imagination, problems with motivation, impaired theory of mind and abnormal emotional responses (Anderson \& Morris, 2006). Thus, CBT for individuals with ASD should be modified according to these limitations (Scattone \& Mong, 2013). These modifications include (1) visual aids, (2) flexibility in both the length and number of treatment sessions (Ozsivadjian \& Knott, 2011), (3) worksheets, (4) multiple-choice in contrast to open-ended questions, (5) highly structured and predictable sessions (Sung et al., 2011), and (6) the patience of the therapist.
From a series of case studies, Ozsivadjian $\&$ Knott, (2011) also emphasised that a thorough understanding of the disorder and the autistic style of neuropsychological processing is perhaps the single most useful tool that a therapist can include in an intervention, as the symptoms of ASD are different in each individual. An example of a positive track record of CBT can be seen in an open trial performed on 20 adolescents with autism. This resulted in significant reductions in the severity of anxiety, as assessed by clinician and parent ratings, from baseline to post-treatment with a one month follow up (Scattone \& Mong, 2013). CBT on 17 ASD children and adolescents conducted by (Sung et al., 2011) also confirmed positive results after a 6-month follow-up. It is important to notice that studies are limited regarding sample sizes and follow-up periods; nevertheless, results are consistent on showing decreasing levels of anxiety post therapy. Even though CBT appears promising, further development of the therapy is needed; principally related to how the therapy can address every unique characteristic of this population. Furthermore, the need for good therapists is also a significant concern in this matter, as one of the determinants in connection with the effectiveness of CBT (Scattone \& Mong, 2013).

\section{Conclusion}

Both anxiety disorders and autism spectrum disorders are naturally heterogeneous in terms of symptoms and behaviours (White et al., 2012, Vasa et al., 2013). Furthermore, underlying causes regarding both disorders, whether biological or environmental, also contribute to the heterogeneity of the disorders, making each case appear different (Przeworski et al., 2011, Geschwind, 2011, Gadow et al., 2010). Meanwhile, the large population of autism spectrum disorders experience high rates of comorbidity with the symptoms of anxiety (Maddox \& White, 2015). A number of typical anxiety symptoms, such as social anxiety, repetitive behaviours and withdrawal play a significant role characterising autism. This overlap and heterogeneity indicate that diagnosis is not easy (Rodgers et al., 2012, Watkins, 2008). Therefore, further research on the measurement of anxiety symptoms in children and adolescents with ASD in addition to the interaction of anxiety and social disability in this population is 
required, so appropriate treatment and intervention can be established to address each specific characteristic of these disorders.

\section{Bibliography}

Alkozei, A., Cooper, P. J., \& Creswell, C. (2014). Emotional reasoning and anxiety sensitivity: Associations with social anxiety disorder in childhood. Journal of Affective Disorders, 152-154, 219-228. http://doi.org/10.1016/j.jad.2013.09.014

Amaral, D. G. (2002). The primate amygdala and the neurobiology of social behavior: implications for understanding social anxiety. Biological Psychiatry, 51(1), 11-17. http://doi.org/10.1016/S0006-3223(01)01307

Amaral, D. G., Bauman, M. D., \& Mills Schumann, C. (2003). The amygdala and autism: implications from non-human primate studies. Genes, Brain and Behavior, 2(5), 295-302. http://doi.org/10.1034/j.1601183X.2003.00043.X

American Psychiatric Association, \& American Psychiatric Association. DSM-5 Task Force. (2013). Diagnostic and statistical manual of mental disorders: DSM-5. (5th ed.). Arlington, Va: American Psychiatric Association.

Anderson, S., \& Morris, J. (2006). Cognitive behaviour therapy for people with Asperger syndrome. Behavioural and Cognitive Psychotherapy, 34(03), 293-303.

Arnott, B., McConachie, H., Meins, E., Fernyhough, C., Couteur, A. L., Turner, M., ... Leekam, S. (2010). The Frequency of Restricted and Repetitive Behaviors in a Community Sample of 15-Month-Old Infants: Journal of Developmental \& Behavioral Pediatrics, 31(3), 223-229.

http://doi.org/10.1097/DBP.0b013e3181d5a2ad

Baker, S. R., \& Edelmann, R. J. (2002). Is social phobia related to lack of social skills? Duration of skill-related behaviours and ratings of behavioural adequacy. British Journal of http://doi.org/10.1348/014466502760379118

Bejerot, S., Eriksson, J. M., \& Mörtberg, E. (2014). Social anxiety in adult autism spectrum disorder. Psychiatry Research, 220(1-2), 705Clinical Psychology, 41(3), 243-257.

707.

http://doi.org/10.1016/j.psychres.2014.08.030

Bellini, S. (2006). The Development of Social Anxiety in Adolescents With Autism Spectrum Disorders. Focus on Autism and Other Developmental Disabilities, 21(3), 138-145. http://doi.org/10.1177/10883576060210030201

Bodfish, J. W., Symons, F. J., Parker, D. E., \& Lewis, M. H. (2000). Varieties of Repetitive Behavior in Autism: Comparisons to Mental Retardation. Journal of Autism and Developmental Disorders, 30(3), 237-243. http://doi.org/10.1023/A:1005596502855

Buitelaar, J. K. (1995). Attachment and Social Withdrawal in Autism: Hypotheses and Findings. Behaviour, 132(5), 319-350. http://doi.org/10.1163/156853995X00595

Cartwright-Hatton, S., McNicol, K., \& Doubleday, E. (2006). Anxiety in a neglected population: Prevalence of anxiety disorders in pre-adolescent children. Clinical Psychology Review, 26(7), 817-833.

http://doi.org/10.1016/j.cpr.2005.12.002

Cervantes, P. E., \& Matson, J. L. (2015). The relationship between comorbid psychopathologies, autism, and social skill deficits in young children. Research in Autism Spectrum Disorders, 10, 101-108. http://doi.org/10.1016/j.rasd.2014.11.006

Cholemkery, H., Mojica, L., Rohrmann, S., Gensthaler, A., \& Freitag, C. (2014). Can Autism Spectrum Disorders and Social Anxiety Disorders be Differentiated by the Social Responsiveness Scale in Children and Adolescents? Journal of Autism and Developmental Disorders, 44(5), 1168-1182. http://doi.org/10.1007/s10803-013-1979-4

Chung, B. H. Y., Drmic, I., Marshall, C. R., Grafodatskaya, D., Carter, M., Fernandez, B. A., ... Scherer, S. W. (2011). Phenotypic spectrum associated with duplication of Xp11.22-p11.23 includes Autism Spectrum Disorder. European Journal of Medical Genetics, 54(5), e516-e520. http://doi.org/10.1016/j.ejmg.2011.05.008

Dadds, M. R., Barrett, P. M., Rapee, R. M., \& Ryan, S. (1996). Family process and child anxiety and aggression: An observational analysis. Journal of Abnormal Child Psychology, 24(6), 715-734. http://doi.org/10.1007/BF01664736

Cite this as:

Hikmiah, Z. Heterogeneity in Anxiety Disorder and Autism Spectrum Disorder: Difference and Overlap. Indonesian Journal of Disability Studies (IJDS).2019: Vol. 6(2): PP 269 - 281. 
Esbensen, A. J., Seltzer, M. M., Lam, K. S. L., \& Bodfish, J. W. (2009). Age-Related Differences in Restricted Repetitive Behaviors in Autism Spectrum Disorders. Journal of Autism and Developmental Disorders, 39(1), 57-66. http://doi.org/10.1007/s10803-008-0599-x

Esther I de Bruin, R. F. F. (2007). High rates of psychiatric co-morbidity in PDD-NOS. Journal of Autism and Developmental Disorders, 37(5), 877-86. http://doi.org/10.1007/s10803-0060215-x

Eussen, M. L., Gool, A. R. V., Verheij, F., Nijs, P. F. D., Verhulst, F. C., \& Greaves-Lord, K. (2013). The association of quality of social relations, symptom severity and intelligence with anxiety in children with autism spectrum disorders. Autism, 17(6), 723-735. http://doi.org/10.1177/1362361312453882

Frick, A., Gingnell, M., Marquand, A. F., Howner, K., Fischer, H., Kristiansson, M., ... Furmark, T. (2014). Classifying social anxiety disorder using multivoxel pattern analyses of brain function and structure. Behavioural Brain Research, 259, 330-335. http://doi.org/10.1016/j.bbr.2013.11.003

Gadow, K. D., DeVincent, C. J., Pisarevskaya, V., Olvet, D. M., Xu, W., Mendell, N. R., ... Hatchwell, E. (2010). Parent-child DRD4 genotype as a potential biomarker for oppositional, anxiety, and repetitive behaviors in children with autism spectrum disorder. Progress in Neuro-Psychopharmacology and Biological Psychiatry, 34(7), 1208-1214. http://doi.org/10.1016/j.pnpbp.2010.06.019

Gaus, V. L. (2011). Adult Asperger Syndrome and the Utility of Cognitive-Behavioral Therapy. Journal of Contemporary Psychotherapy, 41(1), 47-56. http://doi.org/10.1007/s10879-0109159-8

Geschwind, D. H. (2011). Genetics of autism spectrum disorders. Trends in Cognitive Sciences, 15(9), 409-416. http://doi.org/10.1016/j.tics.2011.07.003

Gross, T. F. (2004). The Perception of Four Basic Emotions in Human and Nonhuman Faces by Children With Autism and Other Developmental Disabilities. Journal of Abnormal Child Psychology, 32(5), 469-480. http://doi.org/10.1023/B:JACP.0000037777.17 698.01
Hallett, V., Lecavalier, L., Sukhodolsky, D. G., Cipriano, N., Aman, M. G., McCracken, J. T., ... Scahill, L. (2013). Exploring the Manifestations of Anxiety in Children with Autism Spectrum Disorders. Journal of Autism and Developmental Disorders, 43(10), 2341-2352. http://doi.org/10.1007/s10803-013-1775-1

Helverschou, S. B., \& Martinsen, H. (2011). Anxiety in people diagnosed with autism and intellectual disability: Recognition and phenomenology. Research in Autism Spectrum Disorders, 5(1), 377-387. http://doi.org/10.1016/j.rasd.2010.05.003

Herren, C., In-Albon, T., \& Schneider, S. (2013). Beliefs regarding child anxiety and parenting competence in parents of children with separation anxiety disorder. Journal of Behavior Therapy and Experimental Psychiatry, 44(1), 53-60.

http://doi.org/10.1016/j.jbtep.2012.07.005

Ingalhalikar, M., Parker, W. A., Bloy, L., Roberts, T. P. L., \& Verma, R. (2014). Creating multimodal predictors using missing data: Classifying and subtyping autism spectrum disorder. Journal of Neuroscience Methods, 235, $1-9$.

http://doi.org/10.1016/j.jneumeth.2014.06.030

Kerns, C. M., \& Kendall, P. C. (2012). The Presentation and Classification of Anxiety in Autism Spectrum Disorder. Clinical Psychology: Science and Practice, 19(4), 323347. http://doi.org/10.1111/cpsp.12009

Klin, A. (1991). Young autistic children's listening preferences in regard to speech: A possible characterization of the symptom of social withdrawal. Journal of Autism and Developmental Disorders, 21(1), 29-42. http://doi.org/10.1007/BF02206995

Kumar, R. A., KaraMohamed, S., Sudi, J., Conrad, D. F., Brune, C., Badner, J. A., ... Christian, S. L. (2007). Recurrent 16p11.2 microdeletions in autism. Human Molecular Genetics, 17(4), 628-638. http://doi.org/10.1093/hmg/ddm376

Kyriakopoulos, M., Stringaris, A., Manolesou, S., Radobuljac, M. D., Jacobs, B., Reichenberg, A., ... Frangou, S. (2014). Determination of psychosis-related clinical profiles in children with autism spectrum disorders using latent class analysis. European Child \& Adolescent 
Psychiatry, 24(3), 301-307. http://doi.org/10.1007/s00787-014-0576-1

Libero, L. E., DeRamus, T. P., Lahti, A. C., Deshpande, G., \& Kana, R. K. (2015). Multimodal neuroimaging based classification of autism spectrum disorder using anatomical, neurochemical, and white matter correlates. Cortex, 66, 46-59. http://doi.org/10.1016/j.cortex.2015.02.008

MacNeil, B. M., Lopes, V. A., \& Minnes, P. M. (2009). Anxiety in children and adolescents with Autism Spectrum Disorders. Research in Autism Spectrum Disorders, 3(1), 1-21. http://doi.org/10.1016/j.rasd.2008.06.001

Maddox, B. B., \& White, S. W. (2015). Comorbid Social Anxiety Disorder in Adults with Autism Spectrum Disorder. Journal of Autism and Developmental Disorders, 45(12), 3949-3960. http://doi.org/10.1007/s10803-0152531-5

McPheeters, M. L., Davis, A., Navarre, J. R., \& Scott, T. A. (2011). Family Report of ASD Concomitant with Depression or Anxiety Among US Children. Journal of Autism and Developmental Disorders, 41(5), 646-653. http://doi.org/10.1007/s10803-010-1085-9

Mellings, T. M. ., \& Alden, L. E. (2000). Cognitive processes in social anxiety: the effects of self-focus, rumination and anticipatory processing. Behaviour Research and Therapy, 38(3), 243-257. http://doi.org/10.1016/S00057967(99)00040-6

Modini, M., Abbott, M. J., \& Hunt, C. (2015). A Systematic Review of the Psychometric Properties of Trait Social Anxiety Self-Report Measures. Journal of Psychopathology and Behavioral Assessment, 37(4), 645-662. http://doi.org/10.1007/s 10862-015-9483-0

Muehlmann, A. M., \& Lewis, M. H. (2012). Abnormal repetitive behaviours: shared phenomenology and pathophysiology: Abnormal repetitive behaviours. Journal of Intellectual Disability Research, 56(5), 427-440. http://doi.org/10.1111/j.1365-

2788.2011.01519.x

Naragon-Gainey, K., \& Watson, D. (2011). Clarifying the dispositional basis of social anxiety: A hierarchical perspective. Personality and Individual Differences, 50(7), 926-934. http://doi.org/10.1016/j.paid.2010.07.012
Nilsson, J.-E., Lundh, L.-G., \& Viborg, G. (2012). Imagery rescripting of early memories in social anxiety disorder: An experimental study. Behaviour Research and Therapy, 50(6), 387392. http://doi.org/10.1016/j.brat.2012.03.004

O'Toole, M. S., Hougaard, E., \& Mennin, D. S. (2013). Social anxiety and emotion knowledge: A meta-analysis. Journal of Anxiety Disorders, 27(1), 98-108. http://doi.org/10.1016/j.janxdis.2012.09.005

Ozsivadjian, A., \& Knott, F. (2011). Anxiety problems in young people with autism spectrum disorder: A case series. Clinical Child Psychology and Psychiatry, 16(2), 203-214. http://doi.org/10.1177/1359104511404749

Ozsivadjian, A., Knott, F., \& Magiati, I. (2012). Parent and child perspectives on the nature of anxiety in children and young people with autism spectrum disorders: a focus group study. Autism, 16(2), 107-121. http://doi.org/10.1177/1362361311431703

Piven, J., \& Palmer, P. (1999). Psychiatric disorder and the broad autism phenotype: evidence from a family study of multipleincidence autism families. The American Journal of Psychiatry, 156(4), 557-563. http://doi.org/10.1176/ajp.156.4.557

Przeworski, A., Newman, M. G., Pincus, A. L., Kasoff, M. B., Yamasaki, A. S., Castonguay, L. G., \& Berlin, K. S. (2011). Interpersonal pathoplasticity in individuals with generalized anxiety disorder. Journal of Abnormal Psychology, 120(2), 286-298. http://doi.org/10.1037/a0023334

Rodgers, J., Glod, M., Connolly, B., \& McConachie, H. (2012). The Relationship Between Anxiety and Repetitive Behaviours in Autism Spectrum Disorder. Journal of Autism and Developmental Disorders, 42(11), 24042409. http://doi.org/10.1007/s10803-012-1531$\mathrm{y}$

Rydén, E., \& Bejerot, S. (2008). Autism spectrum disorders in an adult psychiatric population. A naturalistic cross-sectional controlled study. Retrieved from http://www.clinicalneuropsychiatry.org/pdf/03 ryden.pdf

Scaini, S., Belotti, R., \& Ogliari, A. (2014). Genetic and environmental contributions to social anxiety across different ages: A meta-

Cite this as:

Hikmiah, Z. Heterogeneity in Anxiety Disorder and Autism Spectrum Disorder: Difference and Overlap. Indonesian Journal of Disability Studies (IJDS).2019: Vol. 6(2): PP 269 - 281. 
analytic approach to twin data. Journal of Anxiety Disorders, 28(7), 650-656. http://doi.org/10.1016/j.janxdis.2014.07.002

Scattone, D., \& Mong, M. (2013). Cognitive Behavior Therapy in The Treatment of Anxiety for Adolescents and Adults with Autism Spectrum Disorders: CBT for Autism Spectrum Disorders. Psychology in the Schools, 50(9), 923-935. http://doi.org/10.1002/pits.21717

Schneider, B. H. (2009). An observational study of the interactions of socially withdrawn/anxious early adolescents and their friends. Journal of Child Psychology and Psychiatry, 50(7), 799$806 . \quad$ http://doi.org/10.1111/j.14697610.2008.02056.x

Schneier, F. R., Rodebaugh, T. L., Blanco, C., Lewin, H., \& Liebowitz, M. R. (2011). Fear and avoidance of eye contact in social anxiety disorder. Comprehensive Psychiatry, 52(1), 8187.

http://doi.org/10.1016/j.comppsych.2010.04.00 6

Schreier, S.-S., \& Heinrichs, N. (2010). Parental fear of negative child evaluation in child social anxiety. Behaviour Research and Therapy, 48(12), 1186-1193. http://doi.org/10.1016/j.brat.2010.09.001

Seltzer, M. M., Shattuck, P., Abbeduto, L., \& Greenberg, J. S. (2010). Trajectory of Development in Adolescents and Adults with Autism. Mental Retardation and Developmental Disabilities Research Reviews, 10(4), 234-247. http://doi.org/10.1002/mrdd.20038

Shattuck, P., Seltzer, M., Greenberg, J., Orsmond, G., Bolt, D., Kring, S., ... Lord, C. (2007). Change in Autism Symptoms and Maladaptive Behaviors in Adolescents and Adults with an Autism Spectrum Disorder. Journal of Autism and Developmental Disorders, $\quad 37(9), \quad$ 1735-1747. http://doi.org/10.1007/s10803-006-0307-7

Staal, W. G., de Krom, M., \& de Jonge, M. V. (2012). Brief Report: The Dopamine-3-Receptor Gene (DRD3) is Associated with Specific Repetitive Behavior in Autism Spectrum Disorder (ASD). Journal of Autism and Developmental Disorders, 42(5), 885-888. http://doi.org/10.1007/s10803-011-1312-z

Stein, M. B., \& Stein, D. J. (2008). Social anxiety disorder. The Lancet, 371(9618), 1115-
1125. http://doi.org/10.1016/S01406736(08)60488-2

Sukhodolsky, D. G., Scahill, L., Gadow, K. D., Arnold, L. E., Aman, M. G., McDougle, C. J., ... Vitiello, B. (2007). Parent-Rated Anxiety Symptoms in Children with Pervasive Developmental Disorders: Frequency and Association with Core Autism Symptoms and Cognitive Functioning. Journal of Abnormal Child Psychology, 36(1), 117-128. http://doi.org/10.1007/s10802-007-9165-9

Sung, M., Ooi, Y. P., Goh, T. J., Pathy, P., Fung, D. S. S., Ang, R. P., ... Lam, C. M. (2011). Effects of Cognitive-Behavioral Therapy on Anxiety in Children with Autism Spectrum Disorders: A Randomized Controlled Trial. Child Psychiatry \& Human Development, 42(6), 634-649. http://doi.org/10.1007/s10578-0110238-1

Trammell, B., Wilczynski, S. M., Dale, B., \& Mcintosh, D. E. (2013). Assessment and Differential Diagnosis of Comorbid Conditions in Adolescents and Adults with Autism Spectrum Disorders. Psychology in the Schools, 50(9), 936-946. http://doi.org/10.1002/pits.21720

Tyson, K. E., \& Cruess, D. G. (2012). Differentiating High-Functioning Autism and Social Phobia. Journal of Autism and Developmental Disorders, 42(7), 1477-1490. http://doi.org/10.1007/s10803-011-1386-7

Ung, D., Selles, R., Small, B. J., \& Storch, E. A. (2015). A Systematic Review and MetaAnalysis of Cognitive-Behavioral Therapy for Anxiety in Youth with High-Functioning Autism Spectrum Disorders. Child Psychiatry \& Human Development, 46(4), 533-547. http://doi.org/10.1007/s10578-014-0494-y

Vasa, R. A., Kalb, L., Mazurek, M., Kanne, S., Freedman, B., Keefer, A., ... Murray, D. (2013). Age-related differences in the prevalence and correlates of anxiety in youth with autism spectrum disorders. Research in Autism Spectrum Disorders, 7(11), 1358-1369. http://doi.org/10.1016/j.rasd.2013.07.005

Watkins, E. R. (2008). Constructive and unconstructive repetitive thought. Psychological Bulletin, 134(2), 163-206. http://doi.org/10.1037/0033-2909.134.2.163

Cite this as: 
White, S. W., Kreiser, N. L., Pugliese, C., \& Scarpa, A. (2012). Social anxiety mediates the effect of autism spectrum disorder characteristics on hostility in young adults. Autism, 16(5), 453-464. http://doi.org/10.1177/1362361311431951

White, S. W., \& Roberson-Nay, R. (2009). Anxiety, Social Deficits, and Loneliness in Youth with Autism Spectrum Disorders. Journal of Autism and Developmental Disorders, 39(7), 1006-1013. http://doi.org/10.1007/s10803-0090713-8

Wolff, J. J., Botteron, K. N., Dager, S. R., Elison, J. T., Estes, A. M., Gu, H., ... The IBIS Network. (2014). Longitudinal patterns of repetitive behavior in toddlers with autism. Journal of Child Psychology and Psychiatry, 55(8), 945953. http://doi.org/10.1111/jcpp.12207 